\title{
Effects of running time of a cattle-cooling system on core body temperature of cows on dairy farms in an arid environment
}

\author{
X. A. Ortiz, ${ }^{*}$ J. F. Smith, ${ }^{* 1}$ B. J. Bradford, ${ }^{*}$ J. P. Harner,† and A. Oddy \\ ${ }^{*}$ Department of Animal Sciences and Industry, and \\ †Department of Biological and Agricultural Engineering, Kansas State University, Manhattan 66502 \\ $\ddagger$ NADA Al-Othman, Al Ahsa, Saudi Arabia 31982
}

\section{ABSTRACT}

Two experiments were conducted on a commercial dairy farm to describe the effects of a reduction in Korral Kool (KK; Korral Kool Inc., Mesa, AZ) system operating time on core body temperature (CBT) of primiparous and multiparous cows. In the first experiment, KK systems were operated for 18,21 , or $24 \mathrm{~h} / \mathrm{d}$ while CBT of 63 multiparous Holstein dairy cows was monitored. All treatments started at $0600 \mathrm{~h}$, and KK systems were turned off at $0000 \mathrm{~h}$ and $0300 \mathrm{~h}$ for the 18-h and 21-h treatments, respectively. Animals were housed in 9 pens and assigned randomly to treatment sequences in a $3 \times 3$ Latin square design. In the second experiment, 21 multiparous and 21 primiparous cows were housed in 6 pens and assigned randomly to treatment sequences (KK operated for 21 or $24 \mathrm{~h} / \mathrm{d}$ ) in a switchback design. All treatments started at $0600 \mathrm{~h}$, and KK systems were turned off at $0300 \mathrm{~h}$ for the 21 - $\mathrm{h}$ treatments. In experiment 1 , cows in the 24 -h treatment had a lower mean CBT than cows in the 18- and 21-h treatments $\left(38.97,39.08\right.$, and $39.03 \pm 0.04^{\circ} \mathrm{C}$, respectively). The significant treatment by time interaction showed that the greatest treatment effects occurred at $0600 \mathrm{~h}$; treatment means at this time were $39.43,39.37$, and $38.88 \pm 0.18^{\circ} \mathrm{C}$ for $18-, 21-$, and 24 -h treatments, respectively. These results demonstrate that a reduction in KK system running time of $\geq 3 \mathrm{~h} / \mathrm{d}$ will increase CBT. In experiment 2, a significant parity by treatment interaction was found. Multiparous cows on the 24-h treatment had lower mean CBT than cows on the 21-h treatment (39.23 and $39.45 \pm 0.17^{\circ} \mathrm{C}$, respectively), but treatment had no effect on mean CBT of primiparous cows $\left(39.50\right.$ and $39.63 \pm 0.20^{\circ} \mathrm{C}$ for 21 - and 24 -h treatments, respectively). A significant treatment by time interaction was observed, with the greatest treatment effects occurring at $0500 \mathrm{~h}$; treatment means at this time were $39.57,39.23,39.89$, and $39.04 \pm 0.24^{\circ} \mathrm{C}$ for

Received January 29, 2010.

Accepted June 21, 2010.

${ }^{1}$ Corresponding author: jfsmith@ksu.edu 21-h primiparous, 24-h primiparous, 21-h multiparous, and 24-h multiparous cows, respectively. These results demonstrate that multiparous and primiparous cows respond differently when KK system running time decreases from 24 to $21 \mathrm{~h}$. We conclude that in desert climates, the KK system should be operated continuously to decrease heat stress of multiparous dairy cows, but that operating time could be reduced from 24 to $21 \mathrm{~h}$ for primiparous cows. Reducing system operation time should be done carefully, however, because CBT was elevated in all treatments.

Key words: heat stress, evaporative cooling, arid environment

\section{INTRODUCTION}

Ambient temperatures exceeding the thermoneutral zone (TNZ) of dairy cows have detrimental effects on milk production, reproduction, and susceptibility of animals to diseases. Therefore, heat stress is considered a major cause of economic losses in the dairy industry (St-Pierre et al., 2003; Collier, 2007). Core body temperature (CBT) is an indicator used to assess the physiological response to high thermal environments in dairy cows because it is almost constant under thermoneutral conditions. The average CBT of dairy cows in the TNZ ranges from 38 to $39.3^{\circ} \mathrm{C}$, with an average of $38.6^{\circ} \mathrm{C}$ (Dukes, 1947; Settivari et al., 2007).

Dairy production has increased recently in arid climates, especially in places like Saudi Arabia, where farms are growing rapidly in size to meet the demand for milk. In Saudi Arabia, the demand for milk and milk products increases during the summer (Ryan et al., 1992), and because ambient temperatures exceed the TNZ for dairy cows during this period, producers need to use cooling systems to decrease the detrimental effects of heat stress on dairy cows.

Evaporative cooling systems were tested in arid climates and have shown improvement in dairy cow performance (Ryan et al., 1992; Correa-Calderon et al., 2004). Yet little research has evaluated methods of operating these cooling systems in arid environments. 
Korral Kool (KK; model KK1, Korral Kool, Mesa, AZ) is a cooling system that decreases the temperature of air surrounding dairy cows. It injects a fine fog into the air by using fans to drive air through vanes and create a cyclonic motion of air down to the cows (Armstrong, 1994). Because of the evaporative and convective mechanisms this system uses to cool animals, KK is used in environments with high temperature and low humidity. On most farms, the KK system is set to come on at an ambient temperature of $27^{\circ} \mathrm{C}$, but the TNZ of a dairy cow has already been exceeded at this temperature. Because ambient temperature is often higher than the TNZ in arid environments, we hypothesized that KK should work on the basis of operation time.

Primiparous cows respond differently than multiparous cows to evaporative cooling when housed together. Ryan et al. (1992) hypothesized that this difference in response might be the result of dominant older cows demanding better places under the cooling systems, pushing primiparous cows away from the cooling area. Little research has been conducted to evaluate this hypothesis. The objective of these experiments was to investigate the effects of KK operating time on CBT of multiparous and primiparous Holstein cows.

\section{MATERIALS AND METHODS}

Experimental procedures were approved by the Institutional Animal Care and Use Committee at Kansas State University.

Two experiments were conducted on a commercial dairy farm near Al Ahsa, Saudi Arabia, in July and August 2008. Cows were housed in desert barns with a covered area of $10 \mathrm{~m}^{2}$ per cow covering the feeding area as well as part of the dry lot. All pens had KK evaporative cooling systems (model KK1, Korral Kool) located at $6-\mathrm{m}$ intervals. Each unit was $1.30 \mathrm{~m}$ in diameter with a 3-hp motor. The KK units used in this experiment delivered a maximum of $6.8 \mathrm{~L} / \mathrm{m}$ of water and moved $849.5 \mathrm{~m}^{3}$ of air per minute. Weighted curtains were placed on the side of the roof on both sides of the structure to keep the cooled air inside the barn.

Ambient temperature and relative humidity were measured every 15 min with 6 weather stations located throughout the farm. Weather stations were composed of a sensor (Hobo Pro H8, Onset Computer Corp., Bourne, MA) and a solar radiation shield (M-RSA, Onset Computer Corp.).

Core body temperature measurements were obtained at 5-min intervals with data loggers (Hobo U12, Onset Computer Corp.) attached to blank controlled intravaginal drug release devices (Pfizer Animal Health, New York, NY) placed in cows for the duration of the experiment. Each experiment lasted $6 \mathrm{~d}$, with 3 periods of $2 \mathrm{~d}$ each. Cows had $1 \mathrm{~d}$ to acclimate to each treatment, and only the CBT data from the second day were analyzed to minimize carryover effects between treatments.

All animals were milked 4 times daily at 0600, 1200, 1800, and $0000 \mathrm{~h}$. Cows were cooled with KK operated continuously in the holding pen and with soakers in the exit lane. Because of the short duration of these experiments, DMI and milk yield of the animals were not analyzed.

\section{Experiment 1}

The KK systems were operated for 18,21 , or $24 \mathrm{~h} / \mathrm{d}$ while CBT of 63 multiparous Holstein dairy cows (milk production $=44 \pm 20 \mathrm{~kg} / \mathrm{d}$ and $\mathrm{DIM}=120 \pm 85 \mathrm{~d}$ ) was monitored. All treatments started at $0600 \mathrm{~h}$, and KK systems were turned off at $0000 \mathrm{~h}$ and $0300 \mathrm{~h}$ for the 18- and 21-h treatments, respectively. The animals were housed in 9 pens, which were assigned randomly to the treatment sequence in a $3 \times 3$ Latin square design.

\section{Experiment 2}

Twenty-one multiparous (milk production $=36 \pm$ $17 \mathrm{~kg} / \mathrm{d}$ and DIM $=144 \pm 56 \mathrm{~d})$ and 21 primiparous Holstein dairy cows (milk production $=36 \pm 16 \mathrm{~kg} / \mathrm{d}$ and DIM $=94 \pm 38 \mathrm{~d}$ ) were housed in 6 different pens. Cows were housed by parity with 3 pens per parity and 7 cows per pen. Within parity, pens were assigned randomly to a sequence of 2 treatments (KK operated for 21 or $24 \mathrm{~h} / \mathrm{d}$ ) in a switchback design. All treatments started at $0600 \mathrm{~h}$, and KK systems were turned off at $0300 \mathrm{~h}$ for the 21-h treatment.

\section{Statistical Analysis}

Vaginal temperature data in both experiments were analyzed using a repeated measures model with the Mixed Procedure of SAS (version 9.1, SAS Institute, Cary, NC). Compound symmetry covariance structures were used to model repeated measures over time. Significance was declared with a $P$-value $<0.05$, and trends were declared with a $P$-value $>0.05$ and $<0.10$.

For the first experiment, time of day, period, treatment, and time of day $\times$ treatment interaction were included as fixed effects. Cow and pen were assigned as random effects. For the second experiment, data were analyzed by parity with time of day, treatment, and time of day $\times$ treatment interaction included as fixed effects. Animal, pen, and period were assigned as random effects. Pretreatment milk production data were available for cows on experiment 2 , so milk yield and milk yield $\times$ treatment interaction were tested as 


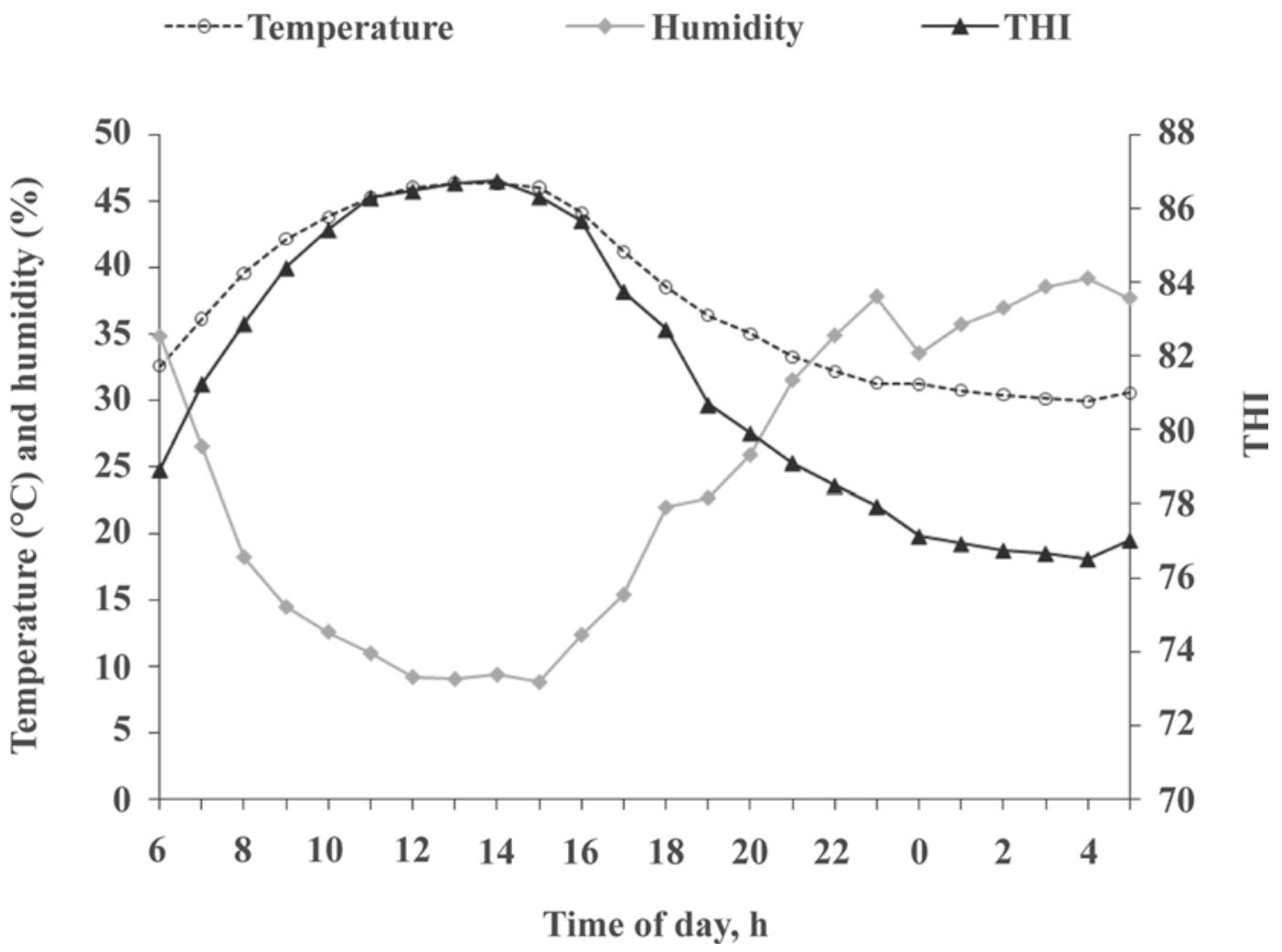

Figure 1. Average ambient temperature, relative humidity, and temperature-humidity index (THI) by hour (experiment 1). Temperature SD $=1.6$; relative humidity $\mathrm{SD}=11.4$; THI calculated from means.

model components; however, these variables were not significant predictors of CBT for primiparous or multiparous cows and were removed from the final model.

\section{RESULTS}

\section{Experiment 1}

In experiment 1, ambient temperature was $37 \pm$ $1.6^{\circ} \mathrm{C}$ (mean $\pm \mathrm{SD}$ ) and relative humidity was $24 \pm$ 11.4 (Figure 1). Cows in the 24-h treatment had a lower CBT $(P<0.05)$ than cows in the 18 - and 21 -h treatments (38.97, 39.08, and $39.03 \pm 0.04^{\circ} \mathrm{C}$, respectively; means \pm SE). There was a significant treatment $\times$ time interaction $(P<0.001)$. The greatest treatment effects occurred at $0600 \mathrm{~h}$; treatment means at this time were $39.43,39.37$, and $38.88 \pm 0.18 \mathrm{C}$ for the 18-, 21-, and 24-h treatments, respectively (Figure 2).

\section{Experiment 2}

In experiment 2, ambient temperature was $35 \pm$ $1.1^{\circ} \mathrm{C}$, and relative humidity was $49 \pm 13.0$ (Figure 3). Multiparous cows on the 24-h treatment had a lower mean CBT $(P<0.007)$ than 21 -h multiparous cows (39.23 and $39.45 \pm 0.17 \mathrm{C}$, respectively), but treatment had no effect $(P>0.19)$ on mean CBT of primiparous cows $\left(39.50\right.$ and $39.63 \pm 0.20^{\circ} \mathrm{C}$ for the 21 - and 24-h treatments, respectively). There was a significant treatment by time interaction for both multiparous and primiparous cows $(P<0.001)$. The greatest treatment effects occurred at $0500 \mathrm{~h}$; treatment means at this time were $39.57,39.23,39.89$, and $39.04 \pm 0.24^{\circ} \mathrm{C}$ for $21-\mathrm{h}$ primiparous, 24-h primiparous, 21-h multiparous, and 24-h multiparous cows, respectively (Figure 4).

\section{DISCUSSION}

Saudi Arabia is one of the regions with the greatest growth in milk production worldwide. In 2007, the Food and Agriculture Organization of the United Nations estimated 1,242,000 $\mathrm{t}$ of milk production per year in Saudi Arabia (FAO, 2009). However, the higher consumption of milk and milk products during summer months has led to seasonal peak production of milk during the hottest months of the year. To accomplish this, producers synchronize cows to calve before the summer months and then breed during summer to maintain milk production for the subsequent lactation (D. V. Armstrong, University of Arizona, Tucson; personal communication). 


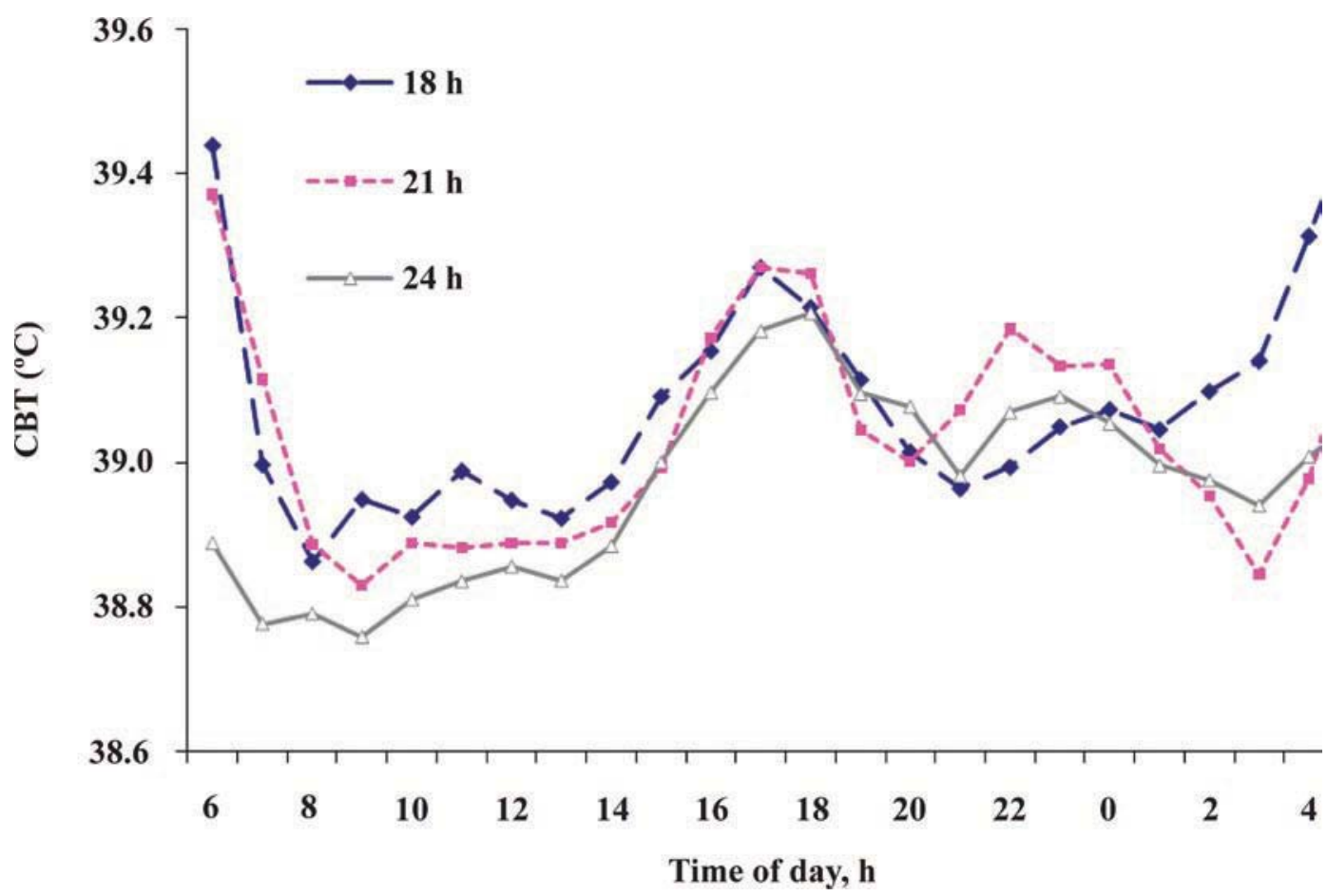

Figure 2. Continuous core body temperature (CBT) of 63 multiparous cows with Korral Kool system (Korral Kool Inc., Mesa, AZ) operated for 18, 21, or $24 \mathrm{~h} / \mathrm{d}$. Treatment by time interaction: $P<0.001$; SEM $=0.18$ (experiment 1 ). Color version available in the online PDF.

This type of seasonal production system has a great effect on milk production and reproduction because of the high ambient temperatures in this area. The average ambient temperature during summer months in Saudi Arabia $\left(36^{\circ} \mathrm{C}\right)$ is above the TNZ of dairy cows $\left(20^{\circ} \mathrm{C}\right.$;
NRC, 2001), meaning that cows could be negatively affected by heat stress. Previous research has shown that heat-stressed cows have decreased yield as result of reduced nutrient intake and a shift in postabsorptive metabolism and nutrient partitioning (Rhoads et al.,
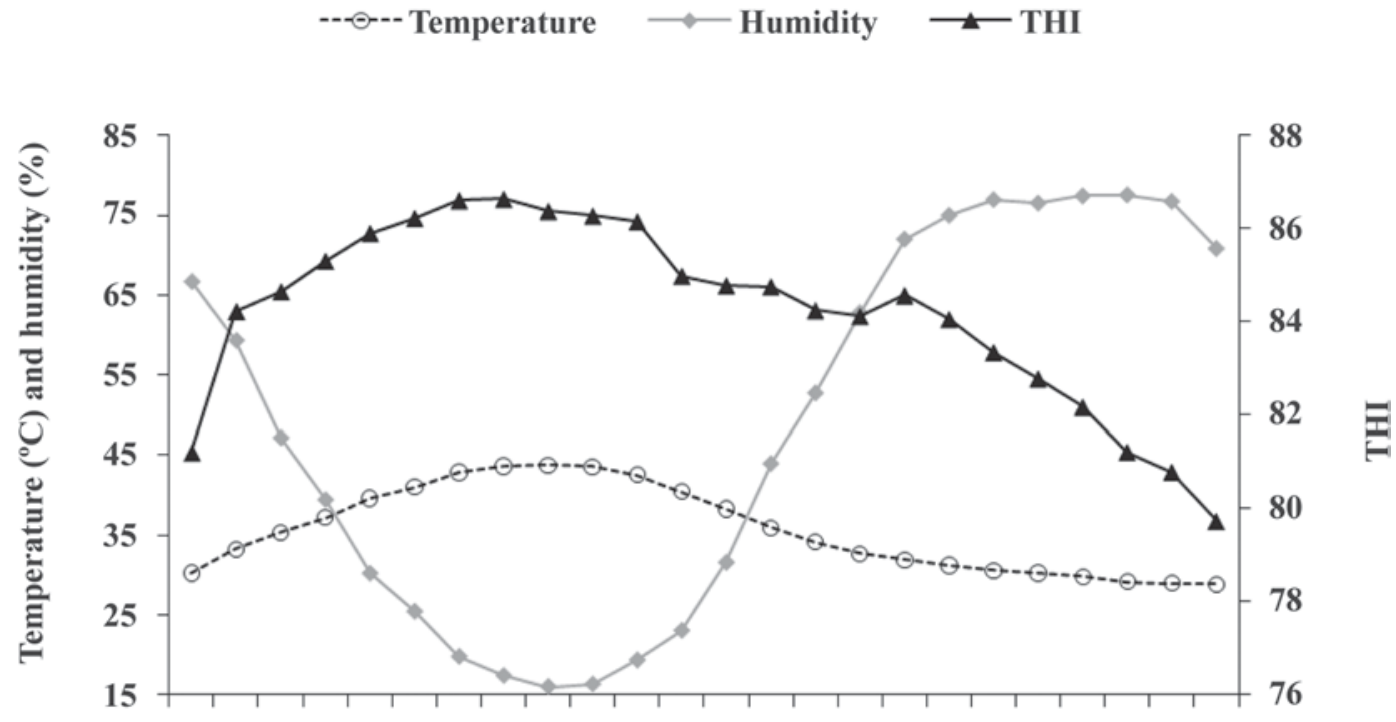

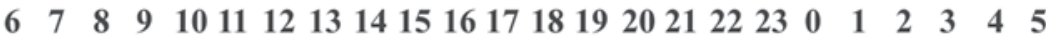

Time of day, h

Figure 3. Average ambient temperature, relative humidity, and temperature-humidity index (THI) by hour (experiment 2). Temperature SD $=1.1$; relative humidity $\mathrm{SD}=13.0$; THI calculated from means. 


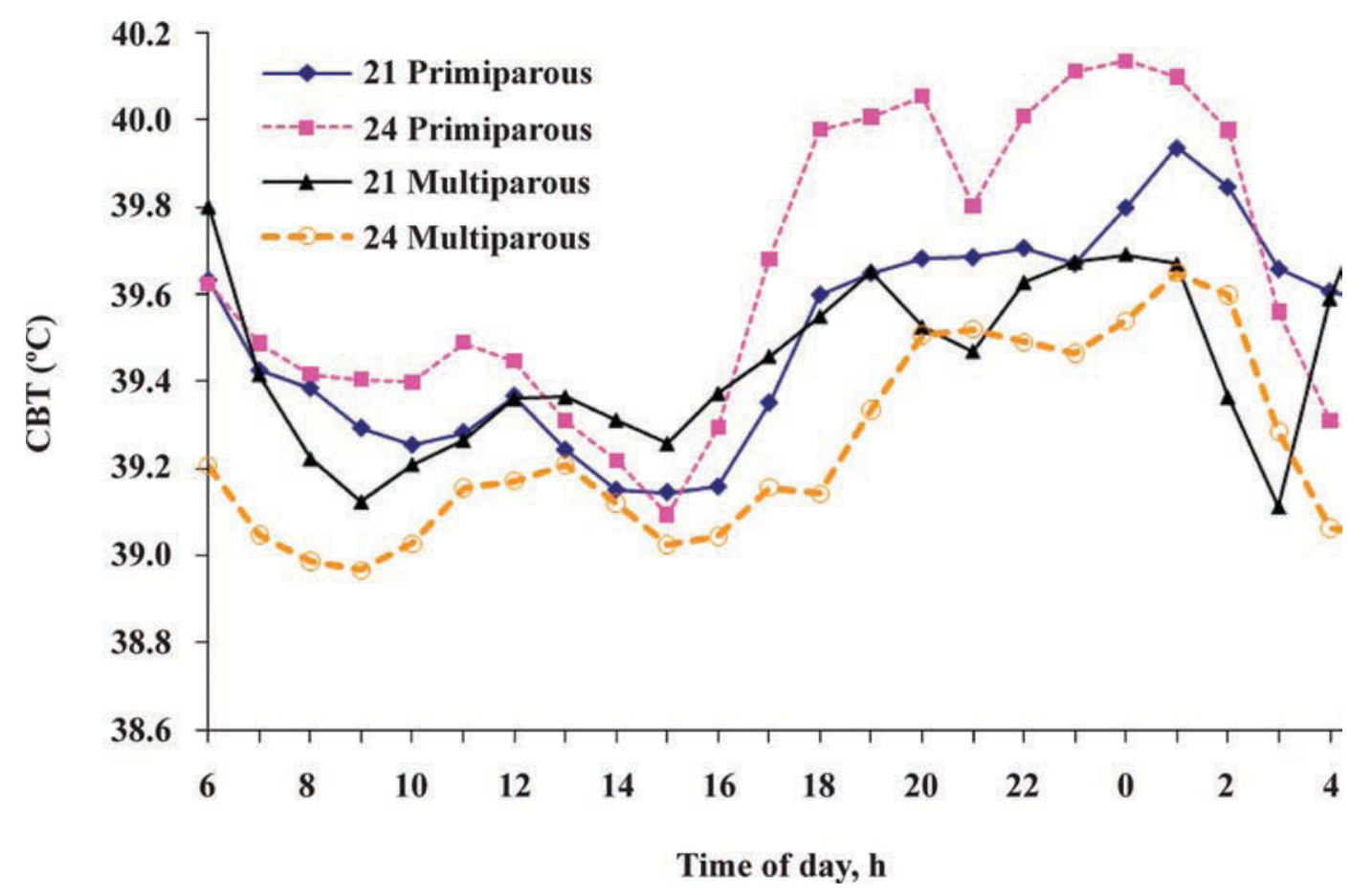

Figure 4. Core body temperature (CBT) of 21 primiparous and 21 multiparous cows with Korral Kool system (Korral Kool Inc., Mesa, AZ) operated for 21 or $24 \mathrm{~h} / \mathrm{d}$ (experiment 2). Treatment by time interaction for primiparous and multiparous cows: $P<0.001 ;$ SEM $=0.24$. Color version available in the online PDF.

2009). Heat stress compromised reproduction in dairy cattle by decreasing the intensity and duration of estrus (Younas et al., 1993; Hansen and Arechiga, 1999) and by reducing the manifestations of estrus (Hansen and Arechiga, 1999). Heat stress decreases conception rates (Morton et al., 2007) and compromises early embryonic development (Hansen et al., 2001).

Genetic and management advances in dairy production have increased the ability to produce milk. This increase in milk yield is accompanied by increases in heat production, making it more difficult for cows to regulate their body temperature during heat stress (Berman, 2005).

Previous research indicated that milk yield and DMI decrease by 1.8 and $1.4 \mathrm{~kg}$ for each $0.55^{\circ} \mathrm{C}$ increase in rectal temperature (Johnson et al., 1963; Umphrey et al., 2001). In arid climates such as that in Saudi Arabia, many cooling systems have been tested (Ryan et al., 1992; Armstrong, 1993; Correa-Calderon et al., 2004) to alleviate the negative effects of heat stress on dairy cows. Of all these systems, evaporative cooling seems to provide the greatest benefit, because it decreases the ambient temperature surrounding the cow and increases the heat exchange between the cow and the environment. It is estimated that at $30^{\circ} \mathrm{C}$, approximately $85 \%$ of the total evaporative heat loss of lactating cows is through evaporation from the skin (Maia et al., 2005).
Core body temperature is a good indicator of the severity of heat stress on cows. An increase in CBT is a physiologic response of dairy cows to heat stress as result of the imbalance between heat energy produced by the animal and amount of heat dissipated. Results from both experiments showed a significant increase in CBT of multiparous cows when KK system operating time decreased from $24 \mathrm{~h}$. This response was not observed in primiparous cows. In both experiments, there was a significant treatment $\times$ time interaction with the greatest differences in CBT occurring at 0600 $\mathrm{h}$ in experiment 1 and at $0500 \mathrm{~h}$ in experiment 2 . The interaction occurred in both primiparous and multiparous cows in the second experiment. The interaction demonstrates the importance of evaluating CBT on an hourly basis versus 24-h averages. Furthermore, the significant effects on CBT early in the morning clearly suggest that the common practice of turning off cooling systems during the night is not always advisable.

In the second experiment, primiparous cows had higher CBT than multiparous cows in all treatments. In a previous experiment, the same response was observed when KK systems cooled primiparous and multiparous cows housed together (Ryan et al., 1992). Based on that experiment, it was suggested that the difference in response was the result of dominant multiparous cows pushing primiparous cows away from the cooling area. 
Because primiparous and multiparous cows were housed separately in the present experiment and a difference in CBT was observed, it is possible that primiparous and multiparous cows exhibit physiological differences during heat stress. Some researchers suggested that because multiparous cows have higher feed intake and milk production than primiparous cows (Chebel et al., 2004; Aguilar et al., 2009), an increase in metabolic heat production leads to an increased susceptibility to heat stress. Nevertheless, the discrepancy in the CBT of primiparous and multiparous cows in this experiment cannot be explained by the literature; future research may clarify these physiological differences.

Even with a 24-h KK system operating time, the CBT of multiparous and primiparous lactating dairy cows exceeded the mean CBT of dairy cows under thermoneutral conditions, suggesting that combining the KK system with a different cooling system might be advantageous in these climatic conditions.

\section{CONCLUSIONS}

Based on these results, we conclude that in desert climate conditions, the KK system should be operated continuously to decrease heat stress of multiparous dairy cows, but that the operating time could be reduced from 24 to $21 \mathrm{~h} / \mathrm{d}$ for primiparous cows. Reducing operation time should be done carefully, because CBT was elevated in all treatments. To decrease the CBT of multiparous and primiparous cows to thermoneutral conditions, it may be necessary to complement the KK system with additional cooling systems such as feed line soakers or additional evaporative cooling on the feed line.

\section{ACKNOWLEDGMENTS}

The authors express their appreciation to NADA AlOthman (Al Ahsa, Saudi Arabia) for their support in development of these experiments.

\section{REFERENCES}

Aguilar, I., I. Misztal, and S. Tsuruta. 2009. Genetic components of heat stress for dairy cattle with multiple lactations. J. Dairy Sci. 92:5702-5711.

Armstrong, D. 1993. Environmental modification to reduce heat stress. Pages 2-7 in Proc. Western Large Herd Management Conference. The Univ. of Arizona, Tucson, AZ.
Armstrong, D. V. 1994. Heat stress interaction with shade and cooling. J. Dairy Sci. 77:2044-2050.

Berman, A. 2005. Estimates of heat stress relief needs for Holstein dairy cows. J. Anim. Sci. 83:1377-1384.

Chebel, R. C., J. E. P. Santos, J. P. Reynolds, R. L. A. Cerri, S. O. Juchem, and M. Overton. 2004. Factors affecting conception rate after artificial insemination and pregnancy loss in lactating dairy cows. Anim. Reprod. Sci. 84:239-255.

Collier, R. J. 2007. Heat stress effects on cattle: What we know and what we don't know. Pages 76-83 in Proc. 22nd Annual Southwest Nutrition and Management Conference. The Univ. of Arizona, Tucson, AZ

Correa-Calderon, A., D. Armstrong, D. Ray, S. DeNise, M. Enns, and C. Howison. 2004. Thermoregulatory responses of Holstein and Brown Swiss heat-stressed dairy cows to two different cooling systems. Int. J. Biometeorol. 48:142-148.

Dukes, H. H. 1947. The Physiology of Domestic Animals. 6th ed. Comstock Publishing Company Inc., Ithaca, NY.

FAO. 2009. FAO Statistical Yearbook; statistics division. Food and Agriculture Organization of the United Nations, Rome, Italy.

Hansen, P. J., and C. F. Arechiga. 1999. Strategies for managing reproduction in the heat-stressed dairy cow. J. Anim. Sci. 77(Suppl. 2):36-50

Hansen, P. J., M. Drost, R. M. Rivera, F. F. Paula-Lopes, Y. M. AlKatanani, C. E. Krininger, and C. C. Chase. 2001. Adverse impact of heat stress on embryo production: Causes and strategies for mitigation. Theriogenology 55:91-103.

Johnson, H. D., A. C. Ragsdale, I. L. Berry, and M. D. Shanklin. 1963 Temperature-humidity effects including influence of acclimation in feed and water consumption of Holstein cattle. Bull. 846, Missouri Agric. Exp. Sta. Res., University of Missouri, Columbia.

Maia, A. S. C., R. G. daSilva, and C. M. Battiston Loureiro. 2005. Sensible and latent heat loss from the body surface of Holstein cows in a tropical environment. Int. J. Biometeorol. 50:17-22.

Morton, J. M., W. P. Tranter, D. G. Mayer, and N. N. Jonsson. 2007. Effects of environmental heat on conception rates in lactating dairy cows: Critical periods of exposure. J. Dairy Sci. 90:2271-2278.

National Research Council. 2001. Nutrient Requirements of Dairy Cattle. 7th ed. Natl. Acad. Sci., Washington, DC.

Rhoads, M. L., R. P. Rhoads, M. J. VanBaale, R. J. Collier, S. R Sanders, W. J. Weber, B. A. Crooker, and L. H. Baumgard. 2009. Effects of heat stress and plane of nutrition on lactating Holstein cows: I. Production, metabolism, and aspects of circulating somatotropin. J. Dairy Sci. 92:1986-1997.

Ryan, D. P., M. P. Boland, E. Kopel, D. Armstrong, L. Munyakazi, R. A. Godke, and R. H. Ingraham. 1992. Evaluating two different evaporative cooling management systems for dairy cows in a hot, dry climate. J. Dairy Sci. 75:1052-1059.

Settivari, R. S., J. N. Spain, M. R. Ellersieck, J. C. Byatt, R. J. Collier, and D. E. Spiers. 2007. Relationship of thermal status to productivity in heat-stressed dairy cows given recombinant bovine somatotropin. J. Dairy Sci. 90:1265-1280.

St-Pierre, N. R., B. Cobanov, and G. Schnitkey. 2003. Economic losses from heat stress by us livestock industries. J. Dairy Sci. 86(E Suppl.):E52-E77.

Umphrey, J. E., B. R. Moss, C. J. Wilcox, and H. H. Van Horn. 2001 Interrelationships in lactating Holsteins of rectal and skin temperatures, milk yield and composition, dry matter intake, body weight, and feed efficiency in summer in Alabama. J. Dairy Sci. $84: 2680-2685$

Younas, M., J. W. Fuquay, A. E. Smith, and A. B. Moore. 1993 Estrous and endocrine responses of lactating Holsteins to forced ventilation during summer. J. Dairy Sci. 76:430-436. 